\title{
Sistemas Integrados de Produção Agropecuária: análise descritiva das ações desenvolvidas por instituições governamentais no Estado de Goiás
}

\author{
Integrated Agricultural Production Systems: descriptive analysis of actions developed by \\ government institutions in the State of Goiás \\ Sistemas Integrados de Producción Agropecuaria: análisis descriptivo de acciones desarrolladas \\ por instituciones gubernamentales en el Estado de Goiás
}

José Carlos de Sousa Júnior ORCID: https://orcid.org/0000-0003-2578-8140
Universidade Estadual de Goiás, Brasil

E-mail: josecarlos.junior@ifgoiano.edu.br

Laysa Lamara da Rocha

ORCID: https://orcid.org/0000-0003-3581-0268 Universidade Estadual de Goiás, Brasil E-mail: laysalamararoh@hotmail.com

Otávio Augusto Martins Oliveira

ORCID: https://orcid.org/0000-0001-7814-2963 Universidade Estadual de Goiás, Brasil E-mail: otaviozootecnia@gmail.com

Rosimery Martins Peixoto

ORCID: https://orcid.org/0000-0002-5247-1846 Universidade Estadual de Goiás, Brasil

E-mail: rosimery29@yahoo.com.br

Rodrigo Medeiros da Silva

ORCID: https://orcid.org/0000-0002-9449-6179 Universidade Estadual de Goiás, Brasil E-mail: rodrigo.medeiros@ueg.br

Fernanda Rodrigues Taveira Rocha ORCID: https://orcid.org/0000-0002-4671-2017 Universidade Estadual de Goiás, Brasil E-mail: fernanda.rocha@ueg.br

Cláudia Peixoto Bueno

ORCID: https://orcid.org/0000-0003-1328-9774 Universidade Estadual de Goiás, Brasil E-mail:vetcpb@gmail.com

Pedro Rogério Giongo

ORCID: https://orcid.org/0000-0002-9042-9120 Universidade Estadual de Goiás, Brasil E-mail: pedro.giongo@ueg.br John Lenon Klein

ORCID: https://orcid.org/0000-0001-8337-4152

Universidade Federal de Santa Maria, Brasil E-mail: johnlenonklein@yahoo.com.br

\begin{abstract}
Resumo
A integração produtiva destaca-se como importante estratégia na alocação de recursos para a produção de alimentos no mundo, aliada aos aspectos sustentáveis que resultam no aumento da produtividade. O Sistema Integrado de Produção Agropecuária (SIPA) é composto por diferentes modelos produtivos tais como Integração Lavoura Pecuária Floresta - ILPF, Integração Lavoura Pecuária - ILP, Integração Pecuária Floresta - IPF, Integração Lavoura Floresta ILF, que sinergicamente proporcionam como benefícios menor custo de produção, maior qualidade do solo e biodiversidade, redução no consumo de água, diminuição na emissão de Gases de Efeito Estufa (GEE), além da otimização da área, considerada principal fator econômico de produção nas atividades agropecuárias. A integração contempla especialmente os benefícios mútuos entre os componentes e as especificidades de cada empreendimento rural, podendo ser adotado por pequeno, médio ou grande produtores. Objetivou-se analisar as atividades das instituições governamentais no Estado de Goiás, condizentes ao tema sistemas integrados de produção. Metodologicamente o estudo possui natureza qualitativa e quanto aos objetivos se enquadra como exploratório e descritivo, por meio de levantamento das ações de instituições ligadas ao setor do agronegócio. Por fim, concluiu-se
\end{abstract}


que a participação das instituições governamentais está vinculada a parcerias institucionais, projetos e parcerias público-privadas, juntamente com instituições de ensino, pesquisa e extensão, que por meio das Unidades de Referência Tecnológicas - URTs, fortalecem a propagação dos modelos de produção integrados.

Palavras-chave: Instituições governamentais; Integração produtiva; Produção agropecuária.

\begin{abstract}
Productive integration stands out as an important strategy in the allocation of resources for food production in the world, combined with sustainable aspects that result in increased productivity. The Integrated Agricultural Production System (SIPA) is composed of different productive models such as Integration of Livestock and Forestry - ILPF, Integration of Livestock and Forestry - ILP, Integration of Livestock and Forestry - IPF, Integration of Forest and Livestock - ILF, which synergistically provide lower production costs as benefits, higher soil quality and biodiversity, reduction in water consumption, reduction in the Emission of Greenhouse Gases (GHG), in addition to the optimization of the area, considered the main economic factor of production in agricultural activities. The integration especially contemplates the mutual benefits between the components and the specifics of each rural enterprise, and can be adopted by small, medium or large producers. The objective was to analyze the activities of government institutions in the State of Goiás, in line with the theme of integrated production systems. Methodologically, the study has a qualitative nature and as for the objectives, it is classified as exploratory and descriptive, through a survey of the actions of institutions linked to the agribusiness sector. Finally, it was concluded that the participation of government institutions is linked to institutional partnerships, projects and public-private partnerships together with educational, research and extension institutions, which through the Technological Reference Units - URTs, strengthen the propagation of models of integrated production.
\end{abstract}

Keywords: Governmental institutions; Productive integration; Agricultural production.

\title{
Resumen
}

La integración productiva se destaca como una estrategia importante en la asignación de recursos para la producción de alimentos en el mundo, combinada con aspectos sustentables que redundan en una mayor productividad. El Sistema Integrado de Producción Agropecuaria (SIPA) está compuesto por diferentes modelos productivos tales como Integración Ganadera y Forestal - ILPF, Integración Ganadera y Forestal - ILP, Integración Ganadera y Forestal - IPF, Integración Forestal y Ganadera - ILF, que de manera sinérgica brindan menores costos de producción como beneficios. , mayor calidad del suelo y biodiversidad, reducción del consumo de agua, reducción de la emisión de Gases de Efecto Invernadero (GEI), además de la optimización del área, considerada el principal factor económico de producción en las actividades agrícolas. La integración contempla especialmente los beneficios mutuos entre los componentes y las particularidades de cada emprendimiento rural, pudiendo ser adoptada por pequeños, medianos o grandes productores. El objetivo fue analizar las actividades de las instituciones gubernamentales en el estado de Goiás, en línea con el tema de los sistemas integrados de producción. Metodológicamente, el estudio tiene un carácter cualitativo y en cuanto a los objetivos, se clasifica como exploratorio y descriptivo, a través de una encuesta de las acciones de las instituciones vinculadas al sector agroindustrial. Finalmente, se concluyó que la participación de las instituciones gubernamentales está vinculada a alianzas institucionales, proyectos y alianzas público-privadas junto con instituciones educativas, de investigación y extensión, que a través de las Unidades de Referencia Tecnológica URT, fortalecen la propagación de modelos de producción integrada.

Palabras clave: Instituciones gubernamentales; Integración productiva; Producción de agricultura.

\section{Introdução}

As mudanças climáticas e o aumento da demanda mundial por alimentos, tem imputado às diversas nações, a necessidade de ajustes nos modelos produtivos que considerem os ecossistemas de referência, ao mesmo tempo em que seja técnica e financeiramente viável, assim como políticas públicas que fomentem a efetividade destas ações (Bustamante et al., 2019).

Neste sentido, o Brasil em participação da Convenção-Quadro das Nações Unidas sobre Mudança do Clima (UNFCCC), acatou de forma voluntária o compromisso de reduzir as emissões de gases de efeito estufa, sendo a Lei ${ }^{\circ} 12.187$ de dezembro de 2009 e o Decreto $\mathrm{N}^{\circ}$ 7.390, de 9 de dezembro de 2010, os marcos legais que institucionalizaram o fomento a ações que promova uma agricultura com baixa emissão de carbono, tais como a recuperação de pastagens degradadas, a ampliação do sistema de Integração Lavoura-Pecuária-Floresta, a expansão no plantio de florestas, entre outros (Brasil, 2009).

Assim sendo, os Sistemas Integrados de Produção Agropecuária (SIPA) emergiram como estratégia para a produção sustentável de alimentos, ao proporcionarem benefícios físicos, químicos e biológicos ao solo, especialmente importante em 
um cenário mundial onde quase 2 bilhões de hectares de terras encontram-se degradadas, segundo relatórios da Food and Agriculture Organization (Fao, 2020).

Além de melhorar a biodiversidade do solo, os sistemas de integração possibilitam o aumento da renda do produtor, por integrar diferentes sistemas produtivos agrícolas, pecuários e florestais dentro da mesma área, ou seja, traz ganhos ambientais, sociais e econômicos para o produtor e para a sociedade de modo geral. Dentre os modelos de integração produtiva têm-se as diferentes configurações, tais como: integração lavoura-pecuária-floresta, lavoura-floresta, lavoura-pecuária e pecuária e floresta (Moraes et al., 2014).

Neste sentido, considerando a representatividade do agronegócio nacional para a economia do país, bem como a importância das atividades agropecuárias para a geração de emprego e renda no Estado de Goiás, que se faz necessário identificar quais as ações desenvolvidas por instituições governamentais de pesquisa e extensão rural, passíveis de implementação pelos produtores goianos. Segundo relatos da Empresa Brasileira de Pesquisa Agropecuária (Embrapa, 2016), o Brasil possui aproximadamente 11,5 milhões de hectares com sistemas integrados de produção agropecuária, sendo que, na região Centro-Oeste o estado de Goiás e o Distrito Federal possuem a menor área com a prática destes sistemas.

Diante do contexto, objetivou-se descrever as atividades desenvolvidas por instituições governamentais, direcionadas ao produtor rural no Estado de Goiás, que subsidiem a difusão e implementação dos modelos integrados de produção agropecuária.

\section{Metodologia}

A metodologia do trabalho baseou-se em uma busca bibliográfica fundamentada com natureza qualitativa, e exploratória com intuito descritivo das informações pesquisadas. O meio de levantamento e seleção das "ações" das instituições ligadas ao setor do agronegócio foram fundamentadas naquelas com caráter de política pública e/ou parceria pública-privada com benefício direto ou potencial de uso aos produtores goianos.

As instituições selecionadas como relevantes e com políticas e ações no Estado de Goiás foram; Embrapa, Emater, Faeg, Senar e Sebrae.

Para obtenção das informações disponibilizadas, realizou-se um levantamento bibliográfico e consulta dos dados disponibilizados nos portais eletrônicos dos referidos órgãos, considerando assim aquelas medidas que envolvam e/ou direcionam políticas para o produtor rural no Estado de Goiás.

\section{Sistemas Integrados de Produção Agropecuária: abordagem histórica e conceitual}

Os Sistemas Integrados de Produção Agropecuária (SIPA), constituem técnicas antigas, que se fundiram com a própria história da agricultura, onde povos caçadores-coletores identificaram que as sementes lançadas ao solo produziam plantas iguais às originais e que os animais domesticados para o fornecimento de carne e leite consumiam os restos das plantas, enquanto, os excrementos dos animais contribuíam para a nutrição do solo, gerando uma sinergia entre as diferentes atividades (Carvalho et al., 2014). Os mesmos autores reforçam que os sistemas integrados são tão antigos quanto à domesticação das plantas e dos animais. Porém, sempre estiveram em evolução, pois o conhecimento de suas propriedades evolui com o conhecimento humano.

De acordo com Balbino et al., (2011) os modelos que integram as atividades agrícola, pecuária e florestal, são historicamente conhecidos na Europa, embora tenham sidos substituídos por atividades desenvolvidas separadamente, fruto da mecanização e intensificação dos sistemas. Sendo creditado aos imigrantes europeus a introdução e adaptação do modelo as condições tropicais de produção associada. Inicialmente, praticado no Rio Grande do Sul, com o cultivo de arroz inundado com pastagens, assim como, a produção consorciada de diferentes culturas por pequenos produtores. 
Todavia, com a modernização e especialização da agricultura, focada no monocultivo, os arranjos produtivos passam a ser conduzidos de forma isolada, prática predominante até os dias atuais, ocasionando a exaustão do solo, redução nos índices de produção vegetal e animal, dentre outras consequências de ordem ambiental e econômica, que exigiram esforços que atenuassem esses impactos. Nesta perspectiva, instituições de pesquisa desenvolveram e aperfeiçoaram técnicas de produção intensiva e sustentável, alinhadas as demandas do produtor (Macedo, 2009).

No Brasil, em termos cronológico, a Integração Lavoura Pecuária (ILP) decorre da década de 1960, por meio de ações da Empresa Brasileira de Pesquisa Agropecuária - Embrapa, direcionadas para a recuperação de áreas degradadas, através da produção de arroz de sequeiro em pastos de braquiária. Em 1980, foi desenvolvido o sistema Barreirão, visando a recuperação de áreas de pastagens degradadas por meio do consórcio de culturas anuais e gado. De acordo com Macedo (2009), o maior benefício do Sistema Barreirão foi em um primeiro momento o de incentivar os produtores para a necessidade de se recuperar/renovar pastagens degradadas e posteriormente para as vantagens da integração lavoura-pecuária.

Em 1990, o pesquisador João Kluthcouski da Embrapa, incrementa o sistema anterior, lançando o Sistema Santa Fé, na Fazenda Santa Fé em Goiás, fundamentado na integração de cultivo de grãos como milho, milheto, sorgo, arroz, soja e girassol, com forrageiras do gênero Brachiaria ou leguminosas e gado (Taguchi \& Ribeiro, 2016). Segundo Tomaz (2017), esse sistema tem como principais objetivos produzir forragem para a entressafra, produzir palhada com qualidade para o Sistema de Plantio Direto (SPD) e produzir grãos. No ano de 2000, a Embrapa associa os sistemas anteriores, inserindo o cultivo do componente arbóreo no entorno dos lotes, sendo esse sistema implantado pela primeira vez na propriedade Santa Brígida em Ipameri. O modelo apresenta a possibilidade de até quatro safras ao ano, sendo grãos (milho e soja), pasto e gado, além da safra de madeira a cada seis ou sete anos (Taguchi \& Ribeiro, 2016).

De acordo com Carvalho et al., (2014) os sistemas de integração podem ser categorizados em quatro modelos diferentes, considerando os componentes que compõem cada arranjo, conforme apresentado no Quadro 1.

Segundo Carvalho et al., (2014), o SIPA é sinônimo de produção sustentável na atualidade, pelo seu papel na produção de alimentos, alinhado ao uso adequado dos recursos naturais e ganhos de produtividade, quando comparado ao modelo intensivo de produção e utilização de recursos. Neste sentido, o tema adquiriu grande relevância no contexto científico, por promover o sequestro de carbono. Assim, a produção integrada vem sendo inserida na agenda de ações para o fomento de uma agricultura com baixa emissão de carbono. Gléria et al., (2017) complementam que com a ampliação da abertura do mercado interacional à commodities, os produtores do Brasil vêm buscando tecnificar seu sistema de produção, visando atender as exigências ambientais e ao mesmo tempo aumentar as fontes de renda.

Tabela 1 - Diferentes configurações de sistemas produtivos integrados

\begin{tabular}{lccl}
\hline Componentes & Sigla & Sistema & \multicolumn{1}{c}{ Características } \\
Lavoura-pecuária & ILP & Agropastoril & $\begin{array}{l}\text { Em rotação, consórcio ou sucessão, na mesma área e } \\
\text { no mesmo ano agrícola. }\end{array}$ \\
Lavoura-floresta & ILF & Silviagrícola & $\begin{array}{l}\text { Consorciação de espécies arbóreas com cultivos } \\
\text { agrícolas (anuais ou perenes). }\end{array}$ \\
Pecuária-floresta & IPF & Silvipastoril & $\begin{array}{l}\text { Integra pastagem e animal com floresta em consórcio. } \\
\text { Lavoura-pecuária-floresta }\end{array}$ \\
ILPF & Agrossilvipastoril & $\begin{array}{l}\text { Integra os componentes agrícola, pecuário e florestal } \\
\text { em rotação, consórcio ou sucessão, na mesma área. }\end{array}$ \\
\hline
\end{tabular}

Fonte: Adaptado de Embrapa (2016) e Balbino et al., (2011). 
Os SIPA são reconhecidamente considerados como modelos produtivos a serem praticados na agropecuária moderna, por congregar em seus sistemas a possibilidade de aumento da renda do produtor, com menor uso de recursos naturais. Todavia, a adoção dos modelos especialmente no Estado de Goiás, ainda se mostra modesta, quando comparado aos demais estados da região Centro-Oeste (Tabela 1). Além disso, segundo dados do mapeamento de áreas de pastagem degradadas realizado pela Embrapa, cerca de 32 milhões de hectares no país estão com algum processo de degradação, dos quais $80 \%$ encontram-se concentrados nos Estados de Goiás, Mato Grosso, Mato Grosso do Sul e Minas Gerais.

Assim sendo, a integração produtiva, envolve a associação intencional, numa perspectiva sistêmica a ser adotada em toda a propriedade ou em parcela da mesma, na qual o resultado do todo (lavoura, pecuária e floresta) adequadamente gerenciado proporciona aumento no retorno econômico para o produtor, e benefícios ambientais e sociais para a comunidade em geral.

Tabela 2 - Comparativo entre áreas sob uso agropecuário e sistemas integrados da região Centro-Oeste.

\begin{tabular}{lcc}
\hline & Uso agropecuário (ha) & Área com integração (ha) \\
\hline Goiás e DF & 19.745 .814 & 943.934 \\
Mato Grosso & 30.957 .213 & 1.501 .016 \\
Mato Grosso do Sul & 19.504 .048 & 2.085 .518 \\
\hline Total & 70.207 .075 & 4.530 .468 \\
\hline
\end{tabular}

Fonte: Adaptado Embrapa, (2016).

\section{Atuação das Instituições na Disseminação dos Sistemas Integrados de Produção}

Dentre as instituições públicas e privadas, a Embrapa e a Emater possuem programas específicos de pesquisa e difusão tecnológica direcionadas à integração produtiva. Por sua vez, as demais instituições atuam como parceiras nas ações pleiteadas, ou promovendo cursos de formação na área e assessoria técnica, constatando que todos os órgãos pesquisados possuem parceria com instituições de ensino público e privado. Em termos gerais, as instituições definem estratégias conforme sua missão e expertise, mas possuem como objetivo comum promover a disseminação de informações acerca dos distintos sistemas de produção integrada, dando visibilidade aos modelos e seus benefícios através de diferentes ações de comunicação. Sob essa ótica, identificou-se práticas presentes em todas as organizações, conforme visualizado na Figura 1.

A Figura 1 mostra que as ações de sensibilização direcionadas ao produtor rural, visam conscientizar e informar sobre os benefícios dos diferentes sistemas, em relação aos atuais, assim como, retratar a possibilidade de adoção conforme particularidades de cada unidade produtiva. Segundo informações disponibilizadas pela Embrapa Meio Ambiente, as estratégias de transferência de tecnologias para ILPF empregadas nos estados de Mato Grosso, Goiás e Distrito Federal, fundamentam-se em três vertentes: a) implantação e condução de sistemas de ILPF nas Unidades de Referência Tecnológicas (URT); b) capacitação continuada (CC) de agentes multiplicadores no tema ILPF; c) ações de sensibilização, motivação, difusão e transferência de conhecimentos (Wruck et al., 2019). Ainda segundo os autores, esse trabalho de difusão e validação das tecnologias ILPF vem sendo contemplado em projetos de transferência de tecnologias contínuos, coerentes e aderentes. 
Figura 1 - Ações comuns adotadas pelas instituições para sensibilizar o produtor.

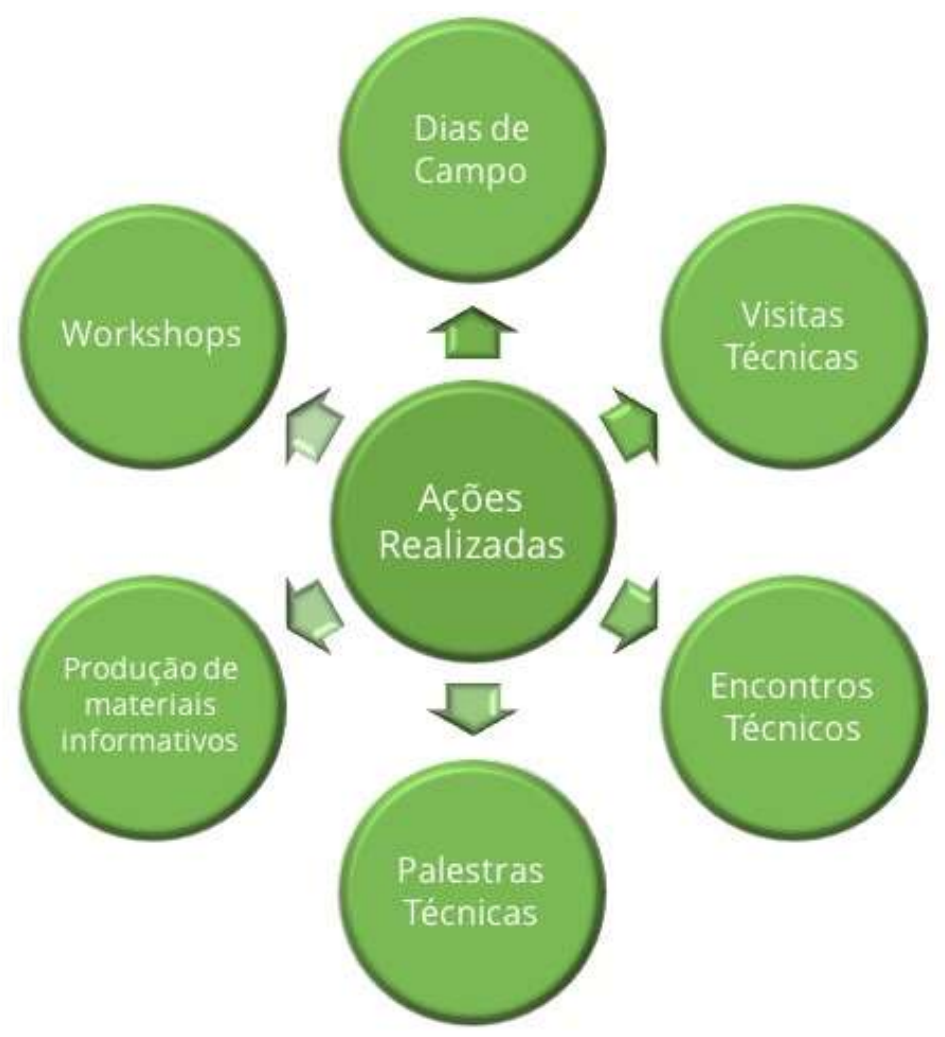

Fonte: Dados da Pesquisa, (2020).

A implantação de URT's constitui um ponto de referência para produtores que desconhecem como os sistemas funcionam na prática. Essa terminologia é usada pela Embrapa e Emater-GO, para referir-se a propriedade particular selecionada, situada em um polo agroeconômico que receberá a tecnologia proposta. De acordo o coordenador de ILPF da Emater, Cosac Júnior, a URT tem a finalidade de apresentar, na prática, as vantagens da adoção do sistema bem como derrubar mitos recorrentes sobre a utilização do ILPF por pequenos produtores rurais.

Por sua vez, Wruck et al. (2019) esclarecem que critérios devem ser seguidos para a condução de uma URT em ILPF, dentre os quais: a propriedade apresente condições para a realização de eventos de transferência de tecnologia (TT); o proprietário demande a adoção do sistema em ILPF, bem como seja receptivo ao uso de tecnologias e intervenções propostas pelos pares; constituição de um grupo gestor da URT, contendo a participação efetiva dos diversos agentes que atuarão na URT; elaboração do plano anual de trabalho (PAT), contemplando as atividades de implantação do sistema no $1^{\circ}$ ano agrícola, e do plano de gerenciamento alinhado ao PAT e ambos validados pelo grupo gestor.

Atualmente, a Embrapa e a Emater possuem URT's em diferentes regiões do estado de Goiás, buscando atuar conforme as especificidades de cada região e suas particularidades socioprodutiva. As unidades com projetos em execução pelas referidas instituições e os respectivos municípios goianos, são expostos na Figura 2. 
Figura 2 - Municípios goianos com Unidades de Referência Tecnológicas da Embrapa e Emater.

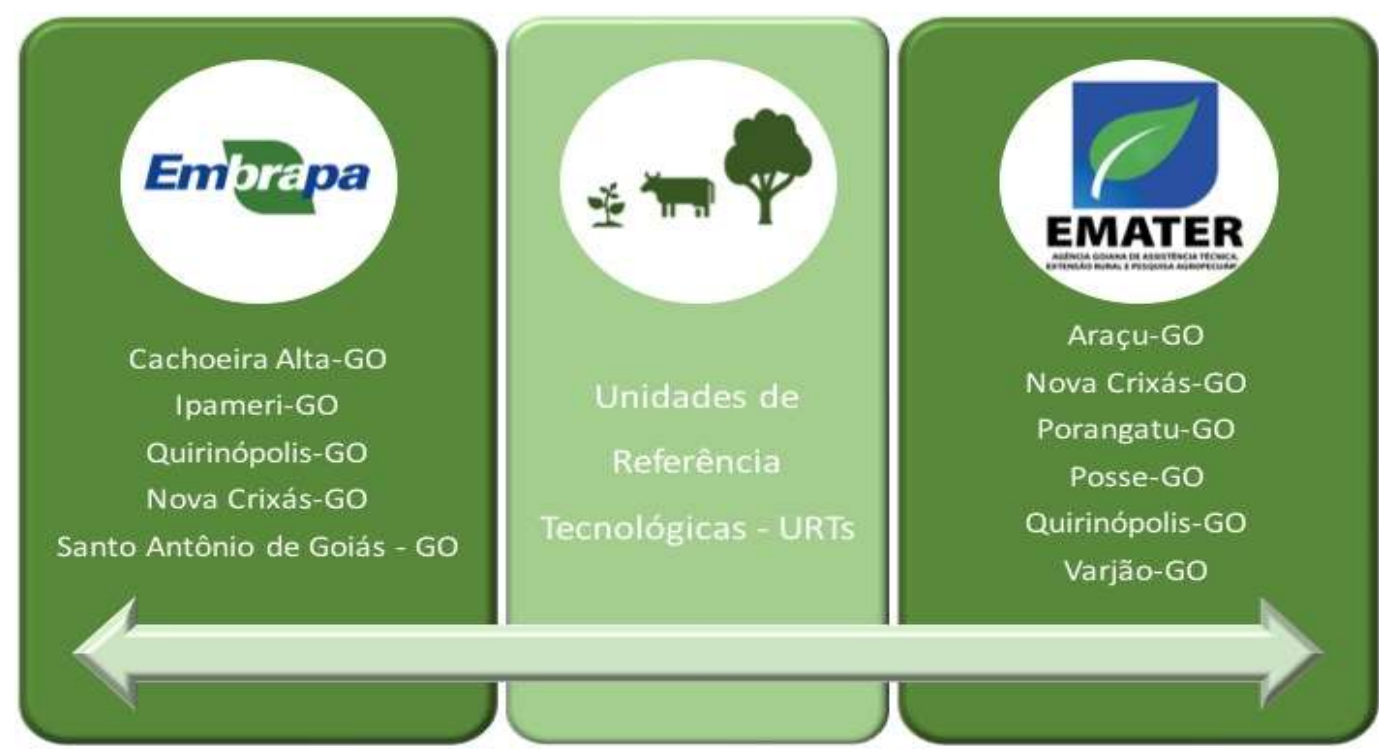

Fonte: Dados da Pesquisa, (2020).

De acordo com dados disponibilizados pela Embrapa Meio Ambiente, considerando as principais configurações dos subsistemas ILPF, nos estados de Mato Grosso, Goiás e Distrito Federal predominam a adoção do modelo ILP, seguido por ILPF, IPF e ILF. Esses resultados são condizentes com os apresentados pela Rede (ILPF) que em 2016 divulgou que em âmbito nacional, dentre as alternativas de sistemas produtivos integrados, a ILP correspondia a $83 \%$ do total identificado, enquanto as configurações ILPF, IPF e ILF as respectivas representatividades em termos de adoção pelos produtores $9 \%, 7 \%$ e $1 \%$.

Ainda segundo a Embrapa (2014), em Goiás, as culturas anuais mais utilizadas dentro do sistema são soja, milho e arroz de terras altas, e quanto as forrageiras as B. brizantha cvs. BRS Piatã e BRS Marandu, e a B. ruziziensis para pastos permanentes e safrinhas, com tendência nos últimos anos agrícolas de cultivo de P. maximum cvs. BRS Zuri e BRS Tamani. Podemos verificar ainda, a predominância na categoria rotação lavoura-pecuária a sucessão soja/milho, soja/consórcio milho com braquiária e soja/braquiária; quanto ao modelo boi safrinha e boi $3^{\circ}$ safra, são usualmente utilizadas as sucessões soja/braquiária e soja/consórcio milho com braquiária. De acordo com Gléria et al. (2017), o destaque no cultivo da soja em sistemas integrados, decorre da boa adaptabilidade e retorno econômico satisfatório desta cultura. Já a cultura do milho, pode trazer problemas devido à alta exigência nutricional no solo no início do processo de integração.

Quanto ao componente arbóreo, é apresentado a preferência pelo cultivo do eucalipto em Goiás, nos sistemas de ILPF e IPF, e mogno africano em menor escala. O Sebrae-GO em parceria com a UFG elaborou uma cartilha que fornece orientação técnica sobre a implantação de cultivos florestais, com foco na cultura do eucalipto, bem como retrata as vantagens de sua produção de maneira consorciada com outras culturas. Estes modelos de integração, além de possibilitar a inserção da cultura florestal, proporciona ao animal maior bem-estar, em virtude do menor estresse térmico. Considerando que na prática, as abordagens destinadas aos animais de produção são categorizadas em 5 domínios: na base o manejo (interação homemanimal), nutrição, instalações e outros fatores, sanidade e ambiência. Este último fator pode potencialmente ser suprido com a adoção dos sistemas integrados pecuária-floresta ou lavoura-pecuária-floresta.

Sob esse enfoque, a Embrapa Gado de Corte, desenvolveu uma marca-conceito representada por um selo, que através de protocolos específicos, aportados nos sistemas silvipastoril ou agrossilvipastoril, garante que durante o processo de produção as emissões de metano entérico foram compensadas pelo crescimento de árvores, que adicionalmente criam um 
ambiente termicamente confortável (Alves et al., 2015). O selo de certificação facilita a identificação do produto junto ao consumidor final, atestando o modelo sustentável de produção, agregando valor ao produto.

\section{Produção Científica Vinculada aos Sistemas Integrados}

Quanto a produção técnico-científica envolvendo a temática abordada, identificamos a participação de diversos pesquisadores que compõem o quadro da Embrapa como autores ou coautores de artigos científicos com recorte regional para o estado de Goiás, vinculados a Embrapa Arroz e Feijão, Embrapa Cerrados, Embrapa Gado de Corte, Embrapa Tabuleiros Costeiros. Predominantemente, os estudos envolvem resultados de experimentos com foco no sistema ILP, cujas discussões contemplam os aspectos físicos, químicos e biológicos do solo sob sistema de integração e em formato convencional de produção comparativamente, com e sem a presença de animais, sendo o sistema uma alternativa viável para a recuperação de áreas com pastagem degradada. Outros estudos, abarcam a utilização de diferentes forrageiras e plantas de cobertura cultivadas na região do Cerrado, a produção de fitomassa e aspectos relacionados a supressão de plantas daninhas. Outras contribuições das pesquisas consistem em apresentar o aumento do teor de matéria orgânica do solo e o incremento gradual da produtividade conforme estudos de Santos et al., (2012); Muniz et al., (2011); Oliveira et al., (2016); Pacheco et al., (2011) entre outros.

Cabe destacar, que estudos desta natureza visam contribuir para a construção de técnicas mais adequadas para a condução das atividades agropecuárias, efetivamente alinhadas ao que preconizam os modelos sustentáveis, sendo especialmente importante no estado de Goiás. Segundo IMB (2017), mais de 60,6\% da área dos estabelecimentos agropecuários de Goiás são ocupados por pastagens naturais ou plantadas, 14,5\% por lavouras, e 21,8\% por matas e florestas (naturais). Todavia, embora a pastagem figure como a principal fonte de nutrientes do rebanho, pois é a forma mais prática e econômica de alimentação dos bovinos, Peron e Evangelista (2004), afirmam que 80\% das pastagens cultivadas no Brasil Central, responsáveis por mais de 55\% da produção de carne nacional, encontrem-se em estado de degradação.

Por sua vez, as instituições analisadas apresentam os mesmos motivos principais para agricultores e pecuaristas aderirem ao sistema, mas em ordem de prioridade diferente, sendo eles: redução do impacto ambiental, recuperação de pastagens, rotação de culturas por necessidade técnica, aumento da rentabilidade por hectare e diminuição do risco financeiro

Quanto aos principais entraves presentes para a adoção dos sistemas destacam-se na região de pecuária goiana: capacidade de endividamento do produtor rural que o impede de acessar as linhas de financiamento do Plano ABC; capacidade plena de consultores em ILPF, aquém da demanda exigida; baixo espírito empreendedor do tradicional do produtor rural goiano, além de fatores de ordem institucional e de infraestrutura tais como excesso de burocracia nas instituições de fomento e péssimas condições das estradas (Wruck et al., 2019). Quanto as possibilidades envolvendo estes modelos produtivos, a Embrapa apresenta como oportunidades e a Emater como resultados esperados, sintetizados na Figura 3. 
Figura 3 - Vantagens na adoção de SIPA de acordo com Emater e Embrapa.

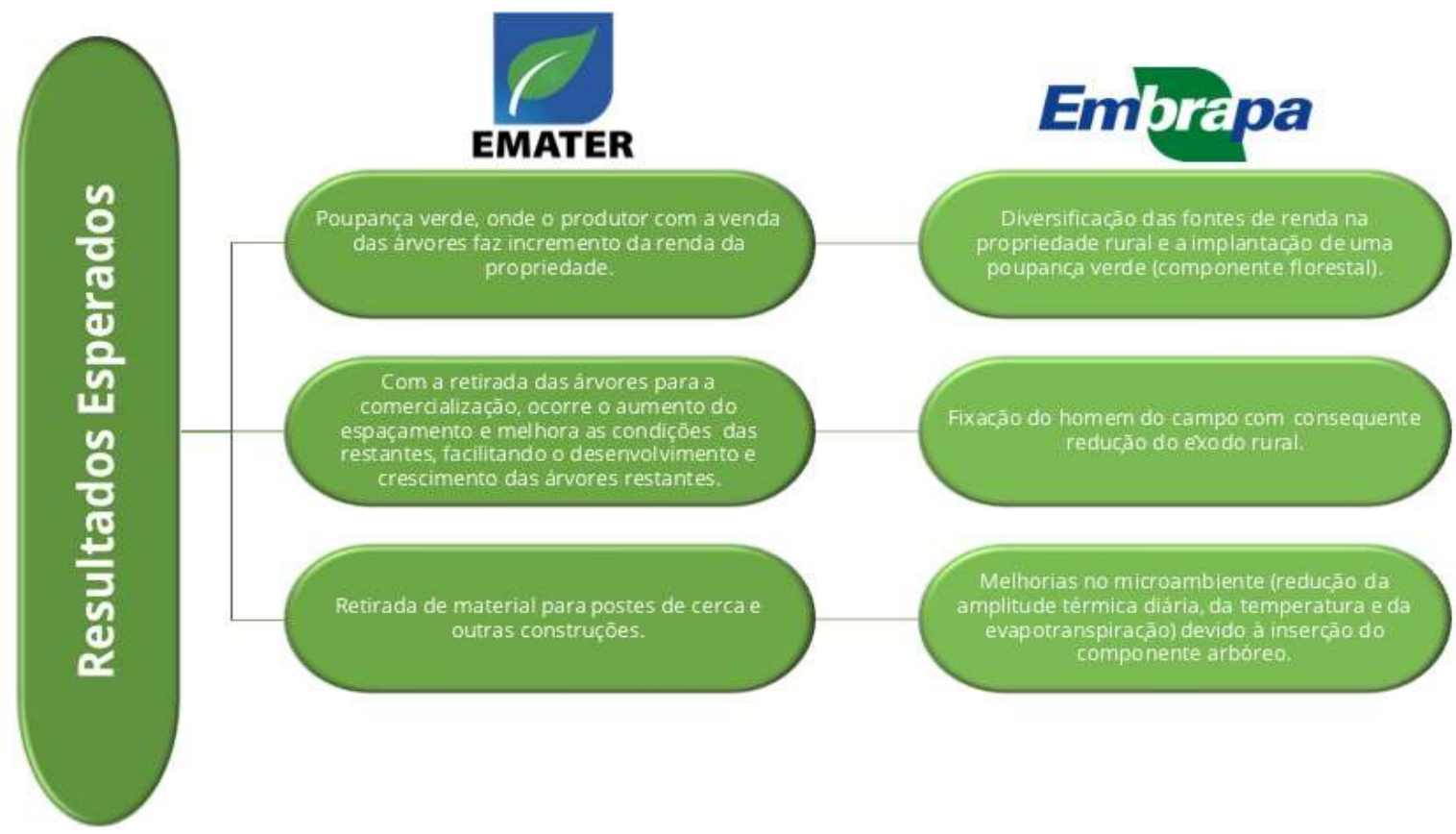

Fonte: Dados da Pesquisa, (2020).

Em termos gerais, conforme demonstrado na Figura 3, observamos um otimismo das instituições analisadas considerando a necessidade do produtor de atuar de forma mais sustentável, ao mesmo tempo em que reduz os riscos financeiros da atividade. Conforme corroboram Vilela et al., (2019), o desenvolvimento de alternativas para o restabelecimento da capacidade produtiva das pastagens cultivadas e de sistemas de manejo mais eficientes para as culturas de grãos é fundamental para alcançar a sustentabilidade e aumentar a eficiência da agropecuária no Cerrado. Ademais, estudos da Embrapa Meio Ambiente, prospectam o aumento da área em ILPF na região Centro-Oeste, enquanto o volume de áreas com pastagem degradadas tende a retrair, sinalizando uma tendência necessária do adequado uso dos recursos naturais para a produção de alimentos, fibras e energia.

\section{Considerações Finais}

As participações das instituições governamentais no Estado de Goiás, para a promoção, difusão e acompanhamento dos SIPA, estão articuladas quanto aos objetivos e os resultados esperados a curto, médio e longo-prazo. As ações são em sua maioria, realizadas por meio das parcerias institucionais e também com o apoio de empresas privadas que atuam neste setor produtivo. Desta forma, mesmo com o protagonismo da Embrapa e Emater no estado em se tratando das ações voltadas ao SIPA, outras instituições também desenvolvem atividades em busca de uma maior participação, por meio de projetos, parcerias público-privadas, instituições de ensino, pesquisa e extensão.

As URTs implantadas em várias localidades do estado corroboram para a propagação deste modelo de produção animal e vegetal, que atualmente figura como uma realidade possível e necessária aos empreendedores rurais.

Como sugestões de trabalhos futuros está a busca de outros agentes (técnicos e extensionistas) que promovam a transferência dessas tecnologias entre as instituições e o produtor, bem como o envolvimento de outros órgãos como as instituições de ensino, pesquisa e extensão. O Estado de Goiás tem apresentado ótimas opções de sistemas aos produtores, ainda que muitas dessas técnicas e tecnologias não tenham chegado diretamente ao produtor. 


\section{Referências}

Alves, F. V., Almeida, de G. R., Laura, V. A., Silva, da V. P., Macedo, M. C. M., Medeiros, de S. R., Ferreira, A. D., Gomes, R. da C., Araújo, de A. R., Montagner, D. B., Bungenstab, D. J., \& Feijó, G. L. D. (2015). Carne carbono neutro: um novo conceito para carne sustentável produzida nos trópicos. Campo Grande, MS: Embrapa Gado de Corte, 1-29.

Balbino, L. C., Cordeiro, L. A. M., Silva, V. P., Moraes, A., Martínez, G. B., Alvarenga, R. C., Kichel, A. N., Fontaneli, R. S., Santos, H. P., Franchini, J. C., \& Galerani, P. R. (2011). Evolução tecnológica e arranjos produtivos de sistemas de integração lavoura-pecuária-floresta no Brasil. Pesquisa Agropecuária Brasileira, Brasília, 46(10), 1-12.

Brasil. (2009) Lei nº 12.187 de dezembro de 2009. Institui a Política Nacional sobre Mudança do Clima - PNMC e dá outras providências. Brasília: DOU.

Bustamante, M. M. C., Silva, J. S., Scariot, A., Sampaio, A. B., Mascia, D. L., Garcia, E., Sano, E., Fernandes, G. W., Durigan, G., \& Roitman, I. (2019). Ecological restoration as a strategy fot mitigating and adapting to climate change: lessons and challenges from Brazil. Mitigation And Adaptation Strategies For Global Change. Springer Science and Business Media LLC. 24(7), 1249-1270.

Carvalho, P. C. F., Moraes, A., Pontes, L. S., Anghinoni, I., Sulc, R. M., \& Batello, C. (2014). Definições e terminologias para Sistema Integrado de Produção Agropecuária. Revista Ciência Agronômica, 45(5), 1040-1046.

Cavalcanti, A. C., Calil, F. N., Borges, J. D., \& Afiune Sobrinho, J. (2019). O eucalipto em Goiás: técnicas, desafios e oportunidades. Cartilha. Sebrae.

Embrapa - Empresa Brasileira de Pesquisa Agropecuária (2014). "Embrapa mapeia degradação das pastagens do cerrado"[online]. https://www.embrapa.br/busca-de-noticias/-/noticia/2361250/embrapa-mapeia-degradacao-das-pastagens-do-cerrado.

Embrapa - Empresa Brasileira de Pesquisa Agropecuária (2016). ILPF em números. http://ainfo.cnptia.embrapa.br/ digital/ bitstream/item/158636/1/2016cpamt-ilpf-em-numeros.pdf

Fao. Food and Agriculture Organization (2010). An international consultation on integrated crop-livestock systems for development. Integrated Crop Management. 13, 1-63. http://www.fao.org/fileadmin/templates/agphome/images/iclsd/documents/crop_livestock_proceedings.pdf

Gléria, A. A., Silva, R. M., Santos, A. P. P., Santos, K. J. G., \& Paim, T. P. (2017). Produção de bovinos de corte em sistemas de integração lavoura pecuária. Archivos de Zootecnia, 66(253), 141-150.

Imb. (2017). Instituto Mauro Borges de Estatísticas e Estudos Socioeconômicos. Agronegócio Goiano. Goiás.

Macedo, M. C. M. (2009). Integração lavoura e pecuária: o estado da arte e inovações tecnológicas. Revista Brasileira Zootecnia, $38,133-146$.

Moraes, A., Carvalho, P. C. F., Lustosa, S. B. C., Lang, C. R., \& Deiss, L. (2014). Research on Integrated Crop-Livestock Systems in Brazil. Revista Ciência Agronômica, Fortaleza, 45(5).

Muniz, L. C., Madari, B. E., Trovo, J. B. de F., Cantanhêde, I. S. de L., Machado, P. L. O. de A., Cobucci, T., \& França, A. F. de S. (2011). Soil biological attributes in pastures of different ages in a crop-livestock integrated system. Pesquisa Agropecuária Brasileira, 46(10), 1262-1268.

Oliveira, W. R. D., Ramos, M. L. G., Carvalho, A. M., Coser, T. R., Silva, A. M. M., Lacerda, M. M., Souza, K. W., Marchão, R. L., Vilela, L., \& Pulrolnik, K. (2016). Dynamics of soil microbiological attributes under integrated production systems, continuous pasture, and native cerrado. Pesquisa Agropecuária Brasileira, 51(9), 1501-1510.

Pacheco, L. P., Leandro, W. M., Machado, P. L. O. A., Assis, R. L., Cobucci, T., Madari, B. E., \& Petter, F. A. (2011). Produção de fitomassa e acúmulo e liberação de nutrientes por plantas de cobertura na safrinha. Pesquisa Agropecuária Brasileira, 46(1), 17-25.

Peron, A. J., \& Evangelista, A. R. (2004). Degradação de pastagens em regiões do cerrado. Ciência e Agrotecnologia, 28(3), 655- 661.

Santos, G. G., Silveira, P. M., Marchão, R. L., Petter, F. A., \& Becquer, T. (2012). Atributos químicos e estabilidade de agregados sob diferentes culturas de cobertura em Latossolo do cerrado. Revista Brasileira. Engenharia Agrícola Ambiental, 16(11), 1171-1178.

Taguchi, V., \& Ribeiro, C. (2016). Infográfico: a evolução da ILPF. <http://revistagloborural.globo.com/Integracao/noticia/2016/04/info grafico-evolucao- dailpf.html.

Tomaz, G. A. (2017). Barreiras a adoção da estratégia de integração lavoura pecuária floresta por agricultores e pecuaristas do estado de Goiás. 2017.91 f. Dissertação (Mestrado em Agronegócio) - Universidade Federal de Goiás, Goiânia.

Vilela, L., Marchão, R. L., Pulrolnik, K., \& Guimarães Júnior, R. (2019). Sistemas de Integração Lavoura-Pecuária: histórico e evolução no Cerrado. In: Skorupa, L. A., \& Manzatto, C. V. (Ed.). Sistemas de integração lavoura-pecuária-floresta no Brasil: estratégias regionais de transferência de tecnologia, avaliação da adoção e de impactos. Brasília: DF, Embrapa.

Wruck, F. J., Pedreira, B. C., Behling, M., Moreira, L. O. M., \& Fernandes, P. C. C. (2019). Sistemas ILPF e transferência de tecnologia nos estados de Mato Grosso, Goiás e Distrito Federal. In: Skorupa, L. A.; Manzatto, C. V. (Ed.). Sistemas de integração lavoura-pecuária-floresta no Brasil: estratégias regionais de transferência de tecnologia, avaliação da adoção e de impactos. Brasília: DF, Embrapa. 